\title{
GEPSUS: Simulation-Based Decision Making System for Air Pollution Accidents
}

\author{
Radovan Stojanović́, Andrej Škraba², Simon Berkowicz ${ }^{3}$, Raffaele de Amicis', Doron Elhanani ${ }^{5}$, \\ Giuseppe Conti ${ }^{4}$, Davorin Kofjač ${ }^{2}$, Marko Dragović ${ }^{1}$, Nedjeljko Lekić ${ }^{1}$ and Gojko Nikolić ${ }^{6}$
}

\author{
${ }^{1}$ University of Montenegro, Faculty of Electrical Engineering, George Washington st. bb., 81000 Podgorica, Montenegro, \\ stox @ ac.me (corresponding author), dragovic @ t-com.me, nedjo @ ac.me
${ }^{2}$ University of Maribor, Cybernetics \& Decision Support Systems Laboratory, Faculty of Organizational Sciences, \\ Kidričeva 55a, 4000 Kranj, Slovenia, andrej.skraba@fov.uni-mb.si, davorin.kofjac@fov.uni-mb.si \\ ${ }^{3}$ Hebrew University of Jerusalem, Arid Ecosystems Research Center, Edmond J. Safra Campus - Givat Ram, \\ Jerusalem 91904, Israel, berkowi@vms.huji.ac.il \\ ${ }^{4}$ Fondazione GraphiTech, Via alla Cascata 56/C, 38123 Trento, Italy, raffaele.de.amicis@ graphitech.it, \\ giuseppe.conti@graphitech.it \\ ${ }^{5}$ EMESCO, 11, Ha-Avoda St. POB 142, Rosh Ha-Ayin, 48017, Israel, e.d.n@ usa.net \\ ${ }^{6}$ University of Montenegro, Faculty of Philosophy, Study Programme for Geography, Danilo Bojovic 3, 81400 Nikšić, \\ Montenegro, gojkorn@ac.me
}

\begin{abstract}
We describe a GIS-based real-time system for emergency response and management of air pollution accidents in an urban area. The system architecture emphasises the integration of meteorological, chemical and GIS data, dispersion modeling, decision-making and geo-spatial visualization. The threat zones, unsafe areas and safe traffic routes are obtained using an improved Gaussian plume model with a decision-making module and then exported to the Google Earth browser via "kml" file format. Several simulation scenarios were conducted and verified for notable industrial sites in Montenegro using recorded meteorological data. The results demonstrate that emergency response authorities can use the proposed methodology and system as a cost effective and accurate support tool in case of industrial or deliberate air pollution incidents.
\end{abstract}

Key words: hazardous gas releases, air pollution simulation, emergency management, GIS

\section{Introduction}

When hazardous gases are released into the atmosphere, whether accidentally or due to a terrorist attack, emergency response authorities require quick and relevant information about the area(s) likely to be affected and anticipated injuries or mortalities. The process is time-critical because of the decision-making loop. This is especially so for urban areas where the population density compounds the potential magnitude of the consequences and complicates evacuation of both the injured and unaffected populace (Pontigia et al., 2010, Abbaspoura and Mansourib, 2005).

Hence there is a pressing need for emergency responders and other civil protection stakeholders to have access to a support system for hazardous gas releases, which will be based on the latest information and communication technologies (ICT). Current air pollutant modeling software applications such as MET, ALOHA, BREEZE, TRACE, SAMS etc. can be applied but provide only a partial solution (Baumann-Stanzer and Stenzel, 2010). They are off-line and predominantly model the pollutant dispersion in $2 \mathrm{D}$ or $3 \mathrm{D}$ space displaying the concentration profiles (plumes) over digital maps. The plumes are static and do not consider the dynamics of the process, primarily the changes in atmospheric conditions and source strength (De Amicis et al., 2009). In addition, they do not support automatic data importing, incorporation of weather forecasts and, most importantly, decision-making required for a successful response.

A useful system for management and control of accidental/deliberate releases of hazardous gases should at least be real-time with the possibility to integrate several subsystems to enhance response accuracy; a) Geographical Information System (GIS), b) system for measurement and monitoring of chemical parameters, c) system for hydrometeorological monitoring and forecasts, d) system for modeling gas dispersion, e) local sensor networks, and e) system for planning emergency responses forces (De Amicis et al., 2009). For many years such

Received: $3^{\text {rd }}$ January 2012; revised $18^{\text {th }}$ February 2012; accepted $3^{\text {th }}$ July 2012 
subsystem integration was a problem due to technological limitations in ensuring rapid and multifaceted data flow and complex modeling computations in real-time.

The GEPSUS (Geographical information processing for Environmental Pollution-related Security within Urban Scale environments) project, funded by the NATO programme Science for Peace, presents one attempt in this direction to provide emergency responders with an integrated system for control and management of hazardous gases accidents, especially in urban areas. It integrates automatic data importing with GIS-based hazardous gas dispersion, simulation and decision-making.

In the present paper, emphasis is placed on accidents caused by industrial and transport facilities, which can be considered as emission point sources. During simulations, the real-time weather conditions are considered such as wind speed and direction as well as atmospheric stability. Decision making is made based on the calculation of threat zones, unsafe area and safe traffic routes. For system validation, Montenegro was selected, specifically several hazardous industrial objects. The same approach can be extended to other hazard sources such as transportation (train derailments, etc), large storage tanks, pipes etc., with small modifications in the dispersion model.

\section{System architecture}

The structure of the GEPSUS system is shown in Fig. 1. The GEPSUS computing facility is the core of the system, which communicates with inputs and generates the outputs. There are four major automatic inputs from: a) Hydrological and Meteorological Service of Montenegro (HMZCG), b) Centre for Ecotoxicological Research of Montenegro (CETI), c) Real Estate Administration of Montenegro (REA) and, d) GEPSUS Sensor Networks (GSN) installed around critical installations. The HMZCG collects automated current weather data and produces forecasts for a national network of weather stations in Montenegro and through the weather forecast models that are part of the European Community and international weather forecast networks. In addition, HMZCG has its own simulation and modeling capabilities including a High Performance Computing (HPC) Centre for generating forecasts for Montenegro every 3 hours at $1 \mathrm{~km}$ resolution. The CETI monitors actual air pollution conditions using a network of automatic telemetric stations measuring the concentration of main gases over Montenegrin cities. The REA provides updated geographical information about geospatial information taken from terrain and cadastral surveys and stored on public servers. GEPSUS communicates with HMZGC, CETI and REA over internet-supported protocol or leased lines. The GSN consists of mobile telemetric stations installed around critical installations. Primarily they measure the wind speed and direction as well as ambient temperature, and transmits data through a GSM network directly to the GEPSUS centre. In future these stations will be equipped with chemical sensors for early warning. HMZCG and CETI provide data on a 10 minute basis, while the GSN has 1 minute averages. GEO data

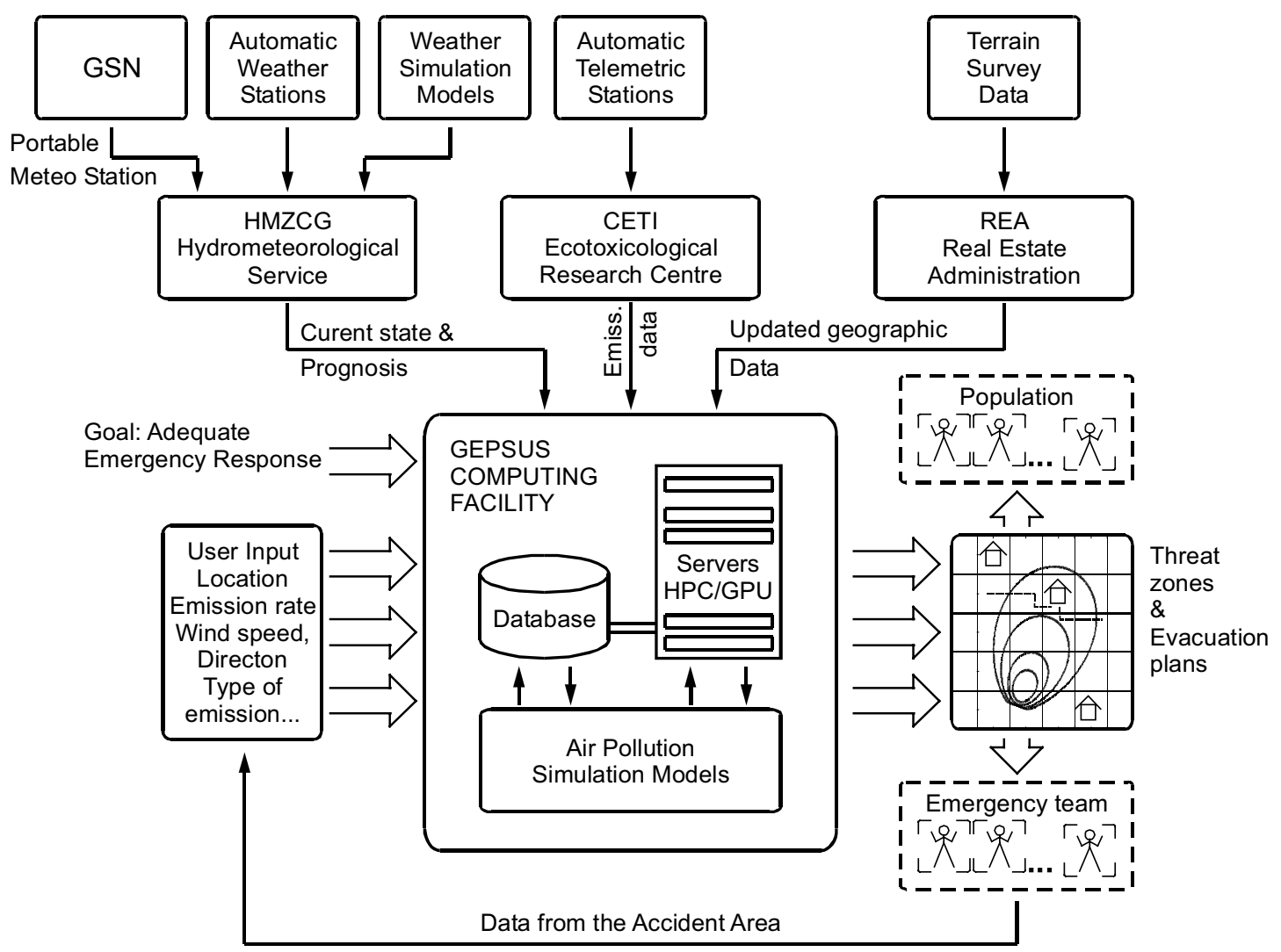

Figure 1: Architecture of the GEPSUS system 
are updated on monthly scale or following important changes in geospatial information and hosts data about strategic buildings and areas such as hospitals, schools and public event areas with potentially high attendance (sports stadium, etc.).

The wind conditions (speed and direction) and their forecasts are considered as primary automatic data because the orientation and geometry of a release plume depends predominantly on them. The HMZCG provides wind conditions at a large scale, eg. for a city or region, while spot wind conditions are traced by local stations within the GSN which sends information in predefined formats readable by the GEPSUS application.

In addition to automatic inputs there are several manual inputs, usually entered by an operator or emergency expert. They provide more information about pollutant source(s) and atmospheric conditions as well the definition of the Levels of Concern (LOCs) - threshold levels of concentration in $\mu \mathrm{g} / \mathrm{m}^{3}$ or ppm. In future these inputs will also be automated. Source data includes accident location (latitude and longitude), description of the pollutant, type of gas and its characteristics, source type (point, line, area, tank or pipe) and its geometry (dimensions), emission rate, source height above aground, release duration, etc. Ground roughness, cloud cover, stability class, inversions, humidity and other parameters are weather conditions that are set manually. LOCs define the threat zones associated for each gas and they are usually standardized such as for the Emergency Response Planning Guidelines (ERPGs) or Acute Exposure Guideline Levels (AEGLs). As an example, for sulfur dioxide $\left(\mathrm{SO}_{2}\right)$ the ERPG-1, ERPG-2 and ERPG-3 levels are $0.3 \mathrm{ppm}, 3 \mathrm{ppm}$ and $25 \mathrm{ppm}$, respectively. Here, other accurate information about an incident can be involved, provided by air pollution experts or rescue crew in the field, who can enter input parameters manually via mobile handheld devices. Fig. 1 does not explicitly show the Emergency room with appropriate servers and equipment where input data are handled and dispersion modeling and decision-making are performed.

\section{Modeling and visualization}

The dispersion modeling is performed in MATLAB starting from generalized Gaussian plume equation (Chitumalla et al., 2008):

$$
\begin{array}{r}
C(x, y, z)=\frac{Q}{2 \pi \mathrm{u} \delta_{\mathrm{y}} \delta_{\mathrm{z}}} e^{-\frac{y^{2}}{2 \delta_{\mathrm{y}}^{2}}}\left(e^{-\frac{(z-H)^{2}}{2 \delta_{\mathrm{z}}^{2}}}+e^{-\frac{(z+H)^{2}}{2 \delta_{\mathrm{z}}^{2}}}\right)+S T \\
S T=\sum_{n=1}^{k} e^{-\frac{\left(z+H-2 n z_{i}\right)^{2}}{2 \delta_{\mathrm{z}}^{2}}}+e^{-\frac{\left(z+H+2 n z_{i}\right)^{2}}{2 \delta_{\mathrm{z}}^{2}}}+e^{-\frac{\left(z-H-2 n z_{i}\right)^{2}}{2 \delta_{\mathrm{z}}^{2}}}+e^{-\frac{\left(z-H+2 n z_{i}\right)^{2}}{2 \delta_{\mathrm{z}}{ }^{2}}}
\end{array}
$$

in which the concentration of pollutant $C(\mathrm{x}, \mathrm{y}, \mathrm{z})\left[\mathrm{g} / \mathrm{m}^{3}\right]$ in point $x[\mathrm{~m}], y[\mathrm{~m}], z[\mathrm{~m}]$ depends on mass emission rate $Q[\mathrm{~g} / \mathrm{s}]$, wind speed $u[\mathrm{~m} / \mathrm{s}]$, dispersion coefficients $\sigma_{y}[m], \sigma_{z}[m]$ and effective stack height $H[\mathrm{~m}]$, which is a sum of actual stack height $h^{s}[\mathrm{~m}]$ and plume rise $\Delta h[\mathrm{~m}], H=h s+\Delta h$. The $S T$ is a summation term related to the inversion from mixing height $z_{i}$, while $k$ is a summation limit for multiple reflection, usually $\leq 4$.

The above equation is used to model the plume impacts from point sources, flare releases, and volume releases, and gives satisfactory results under several assumptions/approximations:

- Steady state process.

- Wind blows in $\mathrm{x}$ direction which is constant in both, speed and direction.

- Transport with the mean wind is much greater than turbulent transport in the $\mathrm{x}$ direction.

- Source emission rate is constant.

- Dispersion coefficients are constant in time and have space dependence towards several approximations, e.g. Pasquill's categories.

- The source emits Chemicals of Concern (COC) at a point in space $\mathrm{x}=\mathrm{y}=0$ and $\mathrm{z}=\mathrm{H}$, where $\mathrm{H}$ is the effective height of the stack

- The COC are inert, non-decaying and non-reactive
- There is no barrier to plume migration

- Mass is conserved across the plume cross section

- Mass within a plume follows a Gaussian distribution in both the crosswind (y direction) and vertical (z direction).

- It is assumed that exit gas temperature is higher than the ambient temperature and varies in the range of 120-260 $\mathrm{C}^{\circ}$

- The wind speed at the point of gas release must be from 6-30 m/s.

- The effective stack high $\mathrm{H}$ is spatially constant, therefore plume rise has a constant value along the $\mathrm{x}$ axis.

Retaining some of the above assumptions, the GEPSUS approach modifies Equation (1) with respect to two main elements:

1) Considering plume rise, $\Delta \mathrm{h}$ is spatially dependant and,

2) Replacing $\sigma_{y}, \sigma_{z}$ with effective values $\sigma_{y_{e f f}}$ and $\sigma_{z_{e f f}}$.

\subsection{Calculation of plume rise and effective dispersion coefficients}

Two categories of smokestack plumes tend to occur: the vertical plume and bent-over plume (Fig 2). They form depending on several parameters such as: stability classes, wind speed, 


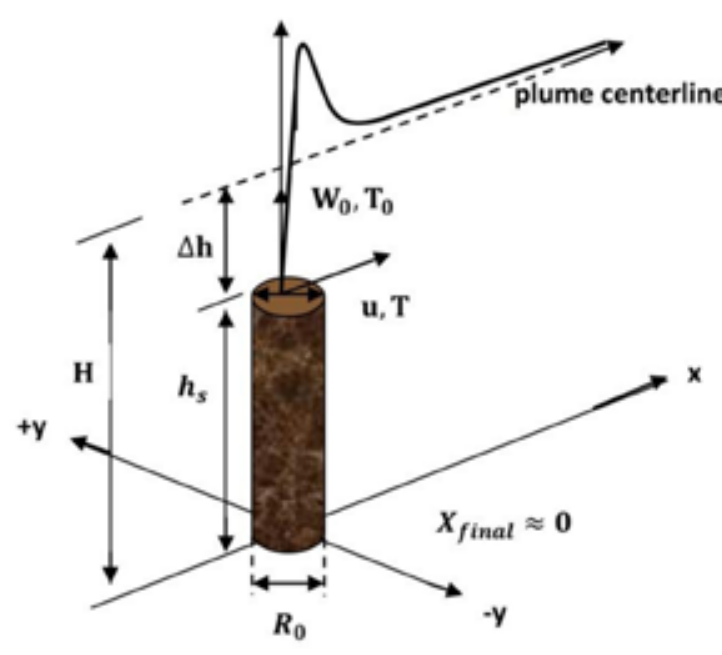

a)

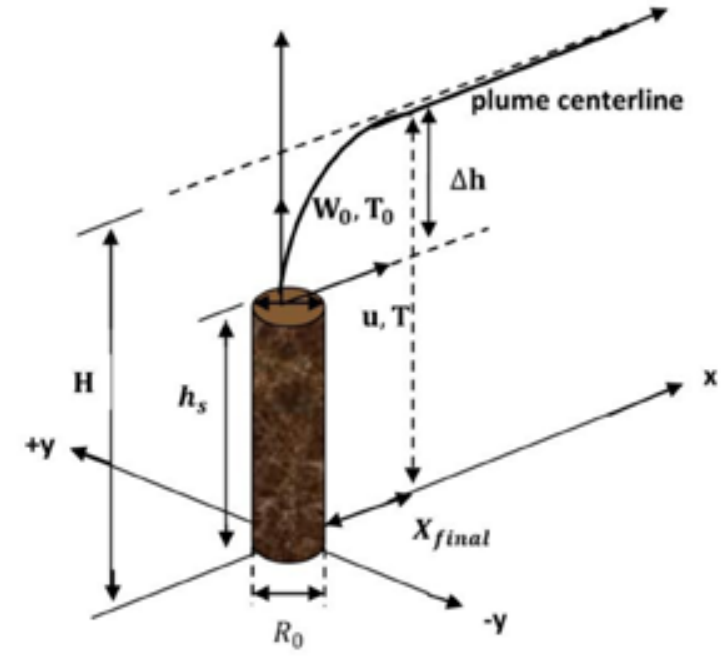

b)

Figure 2: Direct plume (a) and bent-over plume (b).

exit speed of the gas, buoyancy flux parameter, etc. For example, in Pasquill stability classes A to $\mathrm{D}$, when the intensity of wind is significant, the bent-over plume will be dominant, while the vertical form will be present in stable conditions, E or $\mathrm{F}$.
The calculation of plume rise is based on a modified Briggs algorithm (Beychok, 2005) where $\Delta \mathrm{h}$ is calculated for two segments, before $X_{\text {final }}$ - the point of maximum plume rise, and after $\mathrm{X}_{\text {final }}$. Generally, $\Delta \mathrm{h}$ is a complex function and depends of numerous input parameters.

$$
\Delta \mathrm{h}=\mathrm{f}\left(\mathrm{x}, X_{\text {final }}, \mathrm{T}, \mathrm{To}, \mathrm{u}, \mathrm{wo}, \mathrm{g}, \mathrm{Ro}, \frac{\Delta \theta}{\Delta T}, \text { Stability Classes }\right)
$$

where:

$\mathrm{x}$ : downwind distance from plume source $[\mathrm{m}]$

$\mathrm{x}_{\mathrm{final}}$ : downwind distance from plume source to point of maximum plume [m]

$\mathrm{u}$ : wind speed at actual stack height $[\mathrm{m} / \mathrm{s}]$

A, B, C, D, E or F: Pasquill stability classes

$\mathrm{T}_{0}$ : pollutant temperature at the source output $[\mathrm{K}]$

$\mathrm{T}$ : ambient temperature $[\mathrm{K}]$

$\mathrm{W}_{0}$ : pollutant exit speed at stack exit $[\mathrm{m} / \mathrm{s}]$

$\mathrm{R}_{0}$ : diameter of the stack $[\mathrm{m}]$

g: gravitational acceleration $\left[9,81 \mathrm{~m} / \mathrm{s}^{2}\right]$

$\Delta \Theta / \Delta \mathrm{T}$ : coefficient in $[\mathrm{K} / \mathrm{m}]$ which depends on stability classes

The effective values $\sigma_{y_{e f f}}$ and $\sigma_{z_{e f f}}$ are calculated from dispersion coefficients $\sigma_{y}$ and $\sigma_{z}$, taking into consideration the above parameters:

$$
\sigma_{y_{e f f}}, \sigma_{z_{e f f}}=f\left(x, X_{\text {final }}, T, T o, u, w o, g, R o, \sigma_{y} \sigma_{z}, \text { Terrain Type }\right)
$$

where $\sigma_{y}$ and $\sigma_{z}$ are determined from Pasqual-Gifford dispersion coefficients (Briggs, 1965). 
Considering the explained modifications, the concentration $C(\mathrm{x}, \mathrm{y}, \mathrm{z})$ from Equation (1) takes an analytical expression $C^{\prime}(\mathrm{x}, \mathrm{y}, \mathrm{z})$, which is considered as a basic equation in GEPSUS calculations for the case of industrial point sources:

$$
\begin{gathered}
C^{\prime}(x, y, z)=\frac{Q}{2 \pi \mathrm{u} \delta_{\mathrm{y}_{\mathrm{eff}} \delta_{\mathrm{z}_{\mathrm{eff}}}}} e^{-\frac{y^{2}}{2 \delta_{\mathrm{y}_{\mathrm{eff}}}^{2}}\left(e^{-\frac{\left(z-\left(h_{s}+\Delta h\right)\right)^{2}}{2 \delta_{\mathrm{z}_{\mathrm{eff}}}^{2}}}+e^{-\frac{\left(z+\left(h_{s}+\Delta h\right)\right)^{2}}{2 \delta_{\mathrm{z}_{\mathrm{eff}}}^{2}}}\right)+\cdots} \\
\ldots .+T S\left(\Delta \mathrm{h}, \sigma_{y_{\text {eff }}}, \sigma_{z_{e f f}}\right)
\end{gathered}
$$

Usually the summation term TS is neglected and concentration is observed at ground level $(\mathrm{z}=0)$.

\subsection{Visualization and interfacing to GIS}

The overall program for calculation of pollutant concentration according to Equations (1) to (5) was developed in MATLAB and has an algorithmic structure, as given in Fig. 3. The function accepts input parameters and produces mid-term output in the form of a $3 \mathrm{D}$ concentration matrix $C^{\prime}(\mathrm{x}, \mathrm{y}, 0)$ and the final output in the form of a set of contour matrices $\operatorname{Coi}(\mathrm{x}, \mathrm{y}), \mathrm{i}=$ 1,2 ..n. In fact $\operatorname{Coi}(\mathrm{x}, \mathrm{y})$ presents threat zones and is obtained as:

$$
\operatorname{Coi}(x, y)=\left\{\begin{array}{c}
1 \text { for } C^{\prime}(x, y, 0)=T i \\
0 \text { elsewhere }
\end{array}\right.
$$

where $T i$ is LOC for the observed gas in $\frac{\mu g}{m^{3}}$ or ppm.

In order to be displayed by a GIS, the obtained threat zones need to be transferred into format readable by a Geo Browser. In GEPSUS, Google Earth (Tiwary and Colls, 2009) is used because of its wide availability, good graphical interface and possibility to run even on PDA devices. The "kml" file format is used as an interface between MATLAB and Google Earth (http://www.google.com/earth, Accesed, January 12, 2012). It is an open standard officially named the OpenGIS RKML Encoding Standard (OGC KML) (Google Earth, 2012) and is maintained by the Open Geospatial Consortium, Inc. (OGC). In addition the $\mathrm{kml}$ format can be read by a majority of GIS browsers. When $\mathrm{kml}$ files are produced from the application, such as MATLAB custom code, the format should be checked for errors with the XML validator against the kml schema. Before generating $\mathrm{kml}$, the contour graphs (given in meters) should be transferred in latitude-longitude coordinates taking into account source position and then rotated wind angle. As a wind reference angle, north (N) is considered (). Coordinate transformation, rotation and $\mathrm{kml}$ forming are also implemented in MATLAB according to the algorithmic flow given in Fig. 3 (right-side).

\section{Decision making}

The determination of air pollution spread in urban areas is not the only content of the GEPSUS system. As was mentioned earlier, the important issue for emergency response authorities is decision-making. Usually, an individual or group must take decisions but, in many cases, techniques can help him to do so faster and with an increased capability of being more accurate (OpenGL, 2012). In this project phase two algorithms for supporting decision-making are considered:

1. Determination of an unsafe area and,

2. Proposing a safe traffic route between two points.

The unsafe area (UA) is associated with an unsafe perimeter and unsafe arc that are related to each threat zone. Three main parameters should be considered (Fig. 4 a): initial perimeter (P), initial angle (IA), perimeter span (PS) and angle span (AS). $\mathrm{P}$ is associated with each threat zone and presents the distance between source of emission and farthest point in the observed zone. PS is an extension of $\mathrm{P}$ produced by changing input parameters, wind speed, source strength, stability classes etc. AS is predominantly a function of wind direction (WD), while IA is associated with actual WD. As seen in Fig. 4a, the selected threat zone can rotate and translate from $(I A-A S)^{O}$ to $(I A+A S)^{O}$ and from 0 to $P+P S$. As example is presented in Fig. $4 \mathrm{a}$ for $\mathrm{IA}=270^{\circ}$ and $\mathrm{AS}=90^{\circ}, \mathrm{P}$ about $8 \mathrm{~km}$ and $\mathrm{PS}$ about $1 \mathrm{~km}$. The emergency response group should evacuate people from unsafe areas without losing precious time. Using current parameters and weather forecasts, it is important to predict PS and AS as precisely as possible and for such purposes special algorithms and expert modules are used (Škraba et al., 2003). As an example, AS is determined from the standard deviation of WD.

As shown the UA overlaps the critical infrastructure such as roads, schools, student hostels and hospitals that are within the plume hazard area, as example 3 critical objects are covered by UA in Fig. 4a. The attributes of critical infrastructure are determined from emergency data base as well as evacuation instructions and plans. The GEPSUS system uses the records of emergency data base.

The second case concerns taking the shortest safe path in urban traffic. Namely, when an accident happens at some location the traffic needs to be redirected through the safe area. Here GEPSUS developed an algorithm for dynamic routing according to the criteria of the shortest path and safest area, based on an acceptable level of pollutant concentration. The 


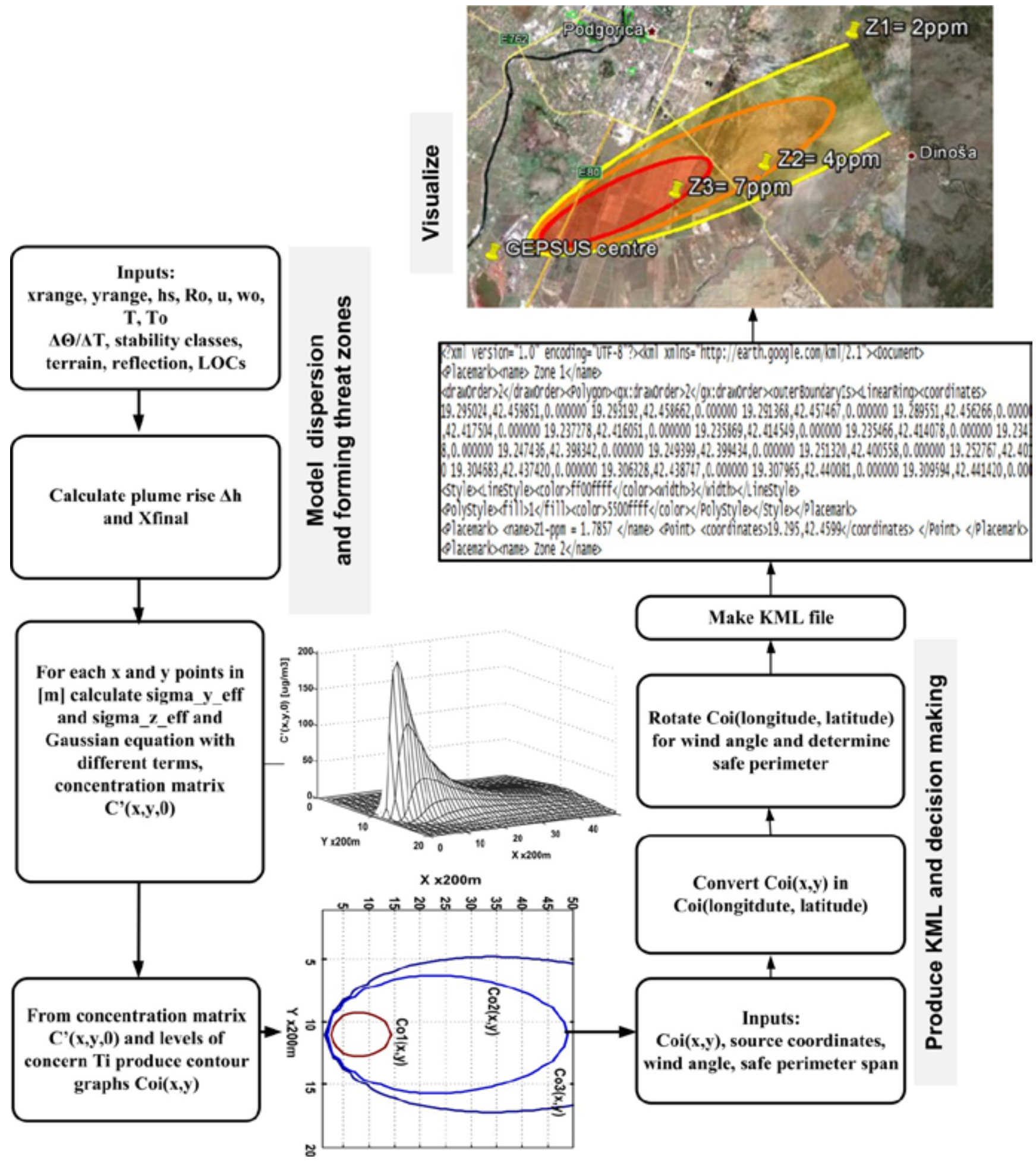

Figure 3: Algorithmic structure of GEPSUS code for modeling and visualization; left side dispersion modeling, right side KML forming with decision-making functions.

algorithm searches for the shortest path between points A and B, Fig. 4b. Concentration thresholds determine the threat zone to be avoided and includes the following steps:

1. Select concentration limit and determine the threat zone
2. Get intersections (nodes) and roads (edges) of the observed area representing possible evacuation routes

3. Remove all nodes and edges inside the polluted area

4. Remove all edges intersecting the polluted area 

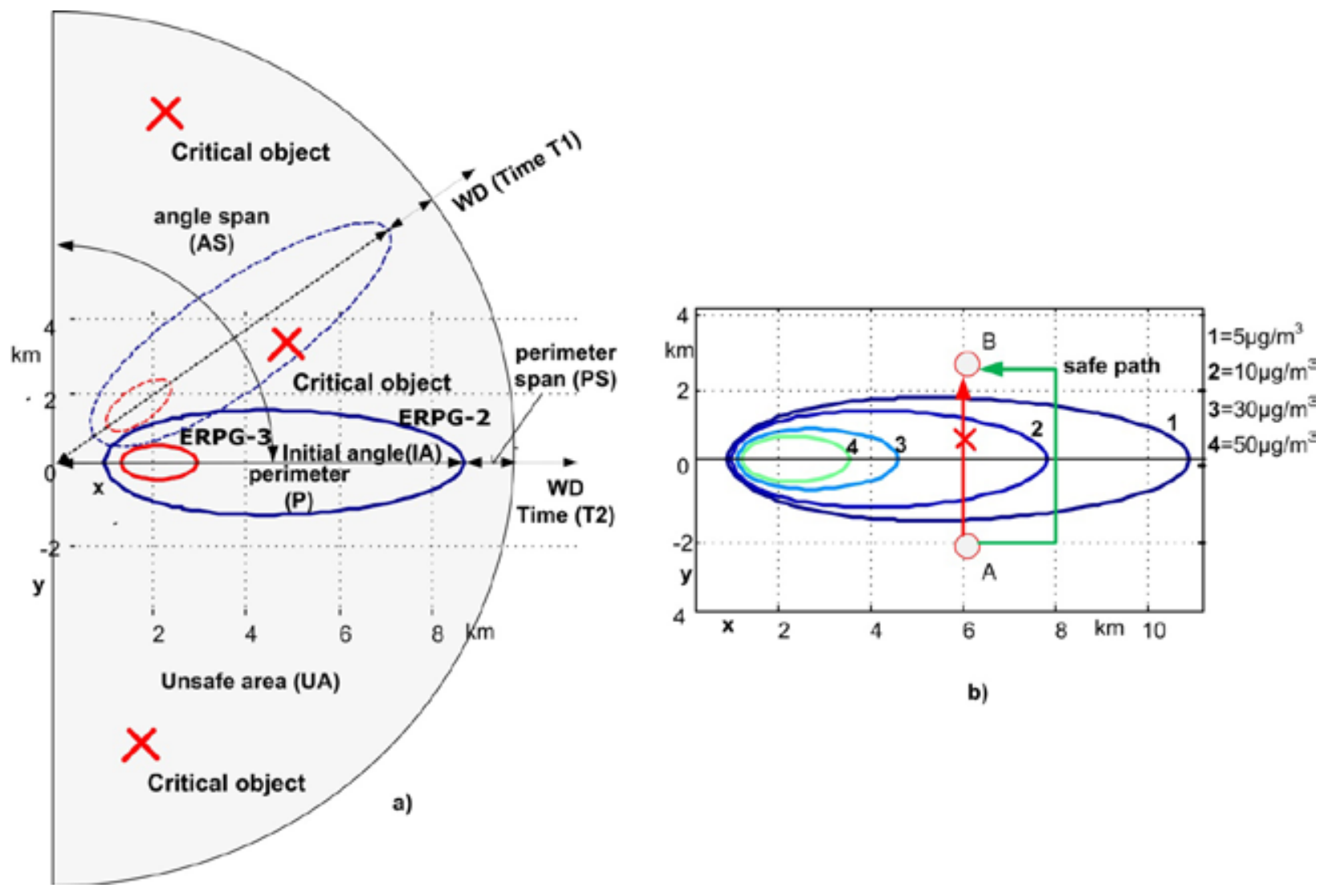

b)

Figure 4: Decision making algorith: a) calculation of unsafe area, b) shortest safe path.

5. Construct a directed graph from remaining nodes and edges where the weight of the edges represents the distance between two nodes

6. Apply the Dijkstra algorithm (Kurashiki et al., 2005; Cormen et al., 2001) to solve the shortest path problem

7. Save shortest route in the $\mathrm{kml}$ format

Fig. $4 \mathrm{~b}$ represents an example of the shortest path (green line) between points $\mathrm{A}$ and $\mathrm{B}$. The concentration limit that should be escaped is zone " 2 " with concentration of $10 \mu \mathrm{g} / \mathrm{m}^{3}$ and more.

\section{Results and validation}

In order to verify the developed dispersion model as well as proposed decision-making techniques, an industrial source in northern Montenegro was used. The Thermo Electric Plant Pljevlja (TEPP) has an output power of $218 \mathrm{MW}$ and is one of the biggest polluters in Montenegro. Due to the lack of filters, harmful gases are released directly into the atmosphere, among others Sulfur Dioxide, $\mathrm{SO}_{2}$.

As a case study, a day when an accident occurred at TEEP has been selected. Because of specific weather conditions, the plume spread over the city, and the CETI station situated in the city center measured increased concentrations of $\mathrm{SO}_{2}$ near the alarm value of $110 \mu \mathrm{g} / \mathrm{m}^{3}$, the level at or above which the general population could experience life-threatening health effects. At the same time, 09:00, the GEPSUS center, received by automatic link the source parameters from the TEPP Command Room and weather conditions from the HMZCG (Table 1, Scenario 1- SC1). The simulation model was started showing a plume spreading and increased zone of $\mathrm{SO}_{2}$ over the city area. The simulation of the initial situation is displayed in Fig. 5. The RED zone (Fig. 5d) is associated with $110 \mu \mathrm{g} /$ $\mathrm{m}^{3}$, (the Montenegrin alarm threshold), ORANGE 26-50 $\mu \mathrm{g}$ / $\mathrm{m}^{3}$ (European Union threshold) and YELLOW $25 \mu \mathrm{g} / \mathrm{m}^{3}$. The WHITE line border unsafe area was obtained by perimeter and angle spans.

In parallel the span perimeter SP and span angle SA for unsafe areas are defined by emergency experts for the purpose of evacuation (WHITE line around the RED zone) (Fig. 6). Simultaneously, taking into account weather forecasts from the HMZCG, SC2 is considered for the next 3 hours, until 12:00. SC2 shows that wind speed and direction will change as well as temperature (Table 1, SC2). The unsafe area under SC2 shifts to the region around the Thermo Plant, with low population density but measures of protection need to be taken in area SC2. At 12:00 the actual weather conditions are taken, Table 1, SC3, shows the difference in wind speed and direction as obtained by forecasts and actual data. However, with a good delineation of the unsafe area, the actual threat zone (RED in SC3) still overlaps with the unsafe area SC2 (See marker Unsafe Area Z3(SC3\&SC2), Fig. 6). 
Table 1: Input data for TEPP during an accident, June 12, 2011

\begin{tabular}{|c|c|c|c|}
\hline Parameter & SC1 & SC2 & SC3 \\
\hline Gas & $\mathrm{SO}_{2}$ & $\mathrm{SO}_{2}$ & $\mathrm{SO}_{2}$ \\
\hline Emision rate Q[g/s] & 918 & 918 & 918 \\
\hline Actual stack height hs [m] & 250 & 250 & 250 \\
\hline Stack diameter Ro [m] & 7.5 & 7.5 & 290 \\
\hline Ambient temp. T $(\mathrm{K})$ & 286.6 & 298.5 & 413 \\
\hline Gas temp on exit T(K) & 413 & 413 & 2 \\
\hline Wind speed at ref point $\mathrm{u}_{\mathrm{r}}(\mathrm{m} / \mathrm{s})$ & 1 & 3.2 & 315 \\
\hline Wind direction $(\mathrm{deg})$ & 225 & 18 & 6.3 \\
\hline Speed of pollutant on exit $(\mathrm{m} / \mathrm{s})$ & 6.3 & 6.3 & B \\
\hline Pasquill stability class & $\mathrm{B}$ & $\mathrm{B}$ & urban \\
\hline Terrain & urban & urban & from ground \\
\hline Reflection & from ground & from ground & $13.334269,19.327522$ \\
\hline Source location $(\mathrm{lat}, \mathrm{lon})$ & $43.334269,19.327522$ & $43.334269,19.327522$ & 90 \\
\hline Perimeter span PS $[\mathrm{m}]$ & 1000 & 1000 & 110 \\
\hline Angle span AS [deg] & 90 & 90 & 110 \\
\hline Critical LOC $\left[\mu \mathrm{\mu g} / \mathrm{m}^{3}\right]$ & 110 & & \\
\hline
\end{tabular}
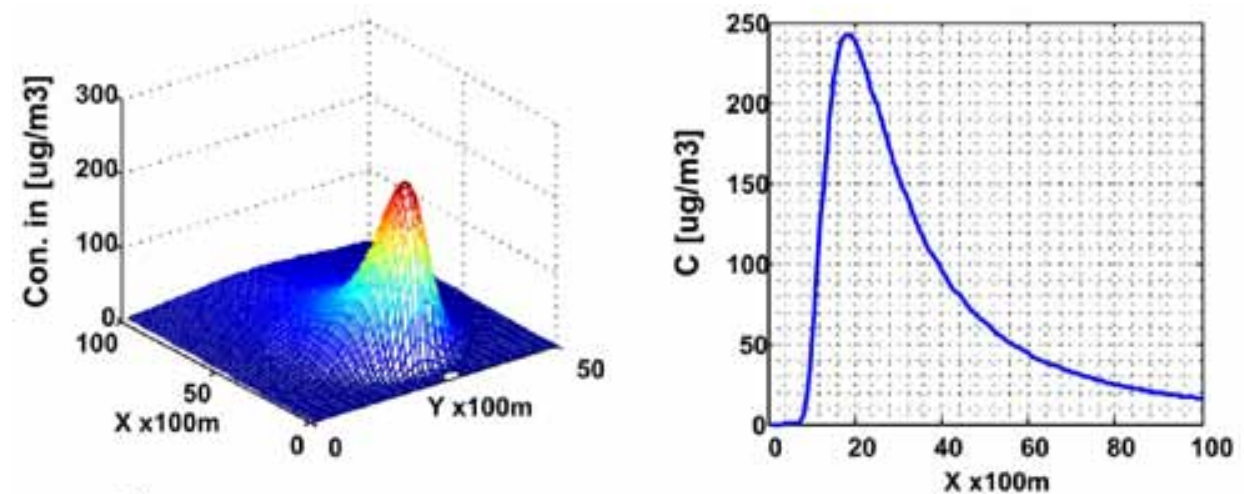

a)

b)

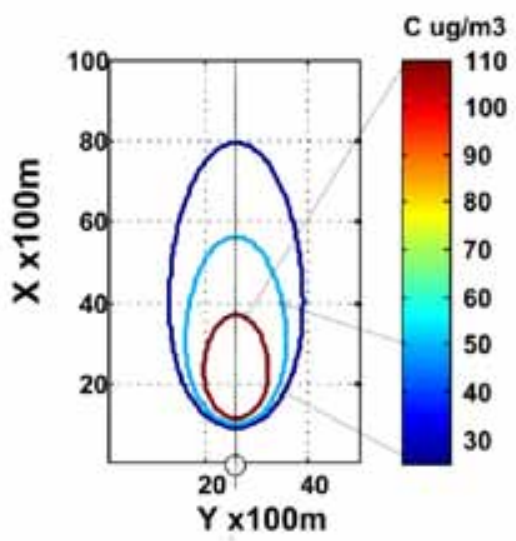

c)

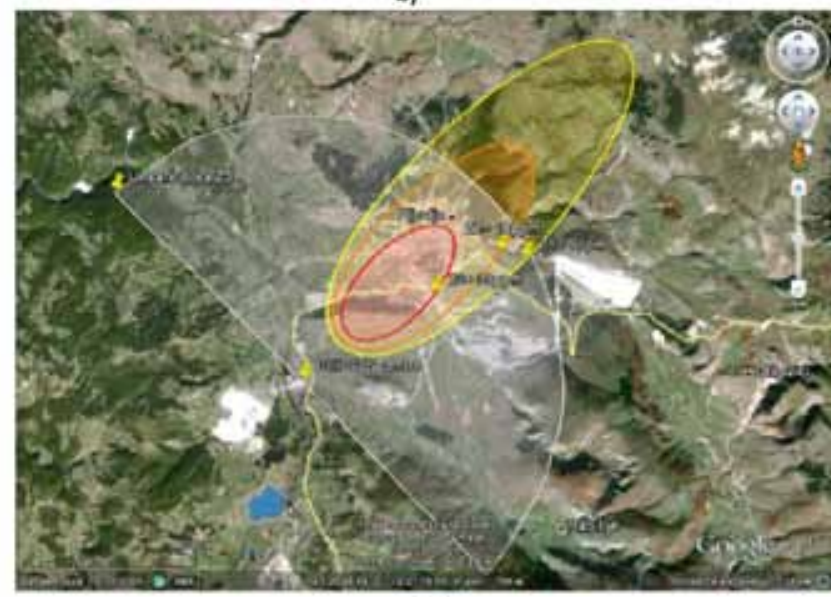

d)

Figure 5: Simulation of scenario SC1: a) 3D concentration plot on ground level, b) downwind profile, c) threat zones for $25 \mu \mathrm{g} / \mathrm{m}^{3}, 50 \mu \mathrm{g} / \mathrm{m}^{3}$ and $110 \mu \mathrm{g} / \mathrm{m}^{3}, d$ ) threat zones plot over Google Earth with $\mathrm{AS}=90^{\circ}$ and PS $1 \mathrm{~km}$. Plume rise $(\Delta h)=681 \mathrm{~m}$, Xfinal $=1110 \mathrm{~m}$, speed on top of stack $u=1.6 \mathrm{~m} / \mathrm{s}$ 


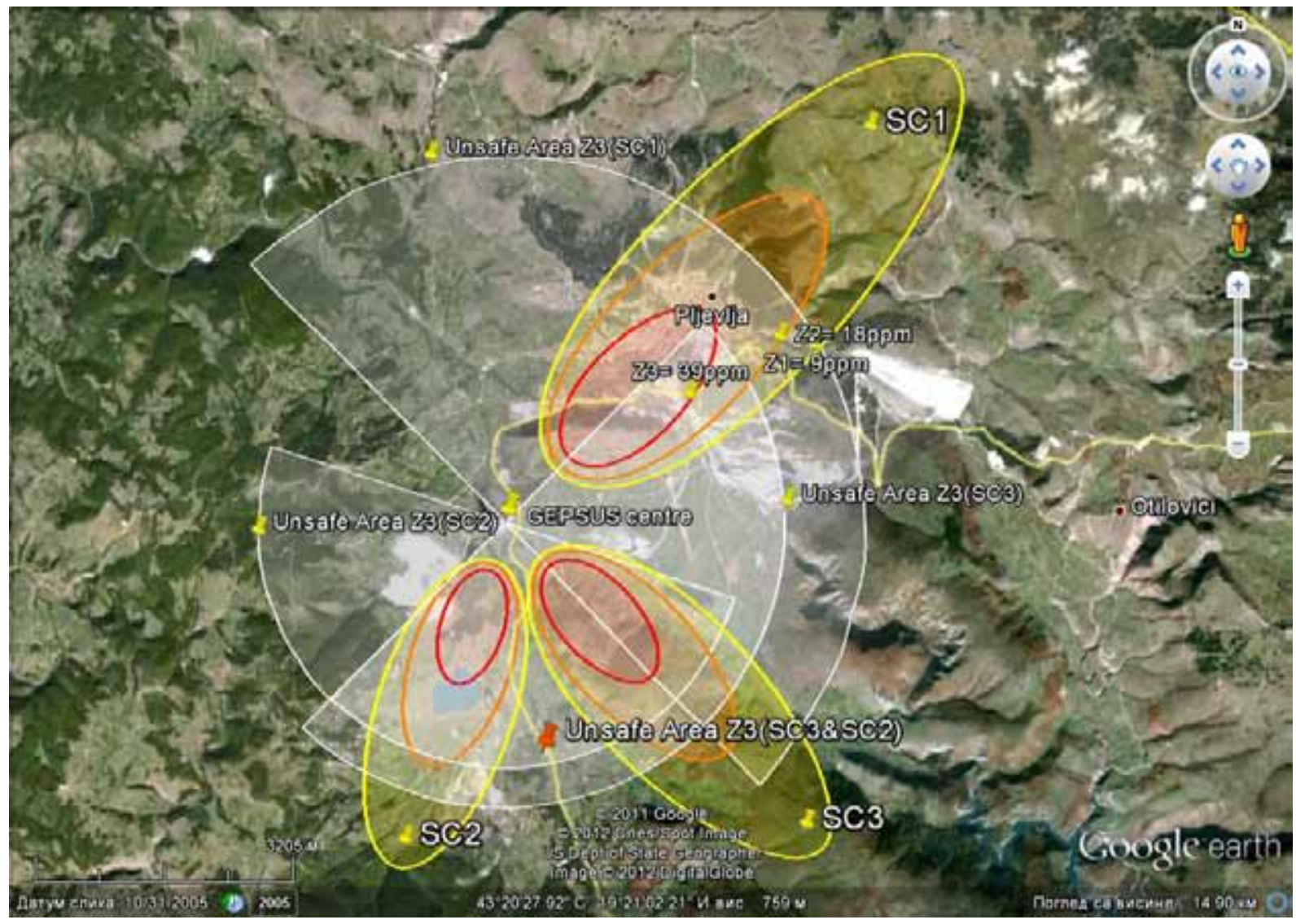

Figure 6: Scenarios SC1, SC2 and SC3 together with unsafe areas

Table 2: Parameters for the release accident at KAP

\begin{tabular}{|c|c|}
\hline Parameter & Type/value \\
\hline Gas & SO2 \\
\hline Emision rate Q [g/s] & 200 \\
\hline Actual stack height hs [m] & 62 \\
\hline Stack diameter Ro [m] & 2.1 \\
\hline Ambient temp. T (K) & 301.5 \\
\hline Gas temp on exit T(K) & 498 \\
\hline Wind speed at ref point (m/s) & 2 \\
\hline Wind direction (deg) & 210 \\
\hline Speed of pollutant on exit (m/s) & 42.3 \\
\hline Pasquill stability class & B \\
\hline Terrain & urban \\
\hline Reflection & from ground \\
\hline Source location (lat., long.) & $42.389000,19.218797$ \\
\hline Critical LOC [ $\left[\mu \mathrm{g} / \mathrm{m}^{3}\right]$ & 50 \\
\hline
\end{tabular}

The second simulation example concerns the shortest traffic route for the case of an uncontrolled $\mathrm{SO}_{2}$ emission from the Aluminum Plant Podgorica (KAP) (Fig. 7), the main polluter in the region of the Montenegrin capital city, Podgorica.
The concentration limit was set to the EU standard of $50 \mu \mathrm{g} /$ $\mathrm{m}^{3}(18 \mathrm{ppm})$ and because of increased $\mathrm{SO}_{2}$ emissions (normally less than $50 \mathrm{~g} / \mathrm{s}$ ) and weather conditions, the RED zone spread over the city. Table 2 shows the source parameters and 


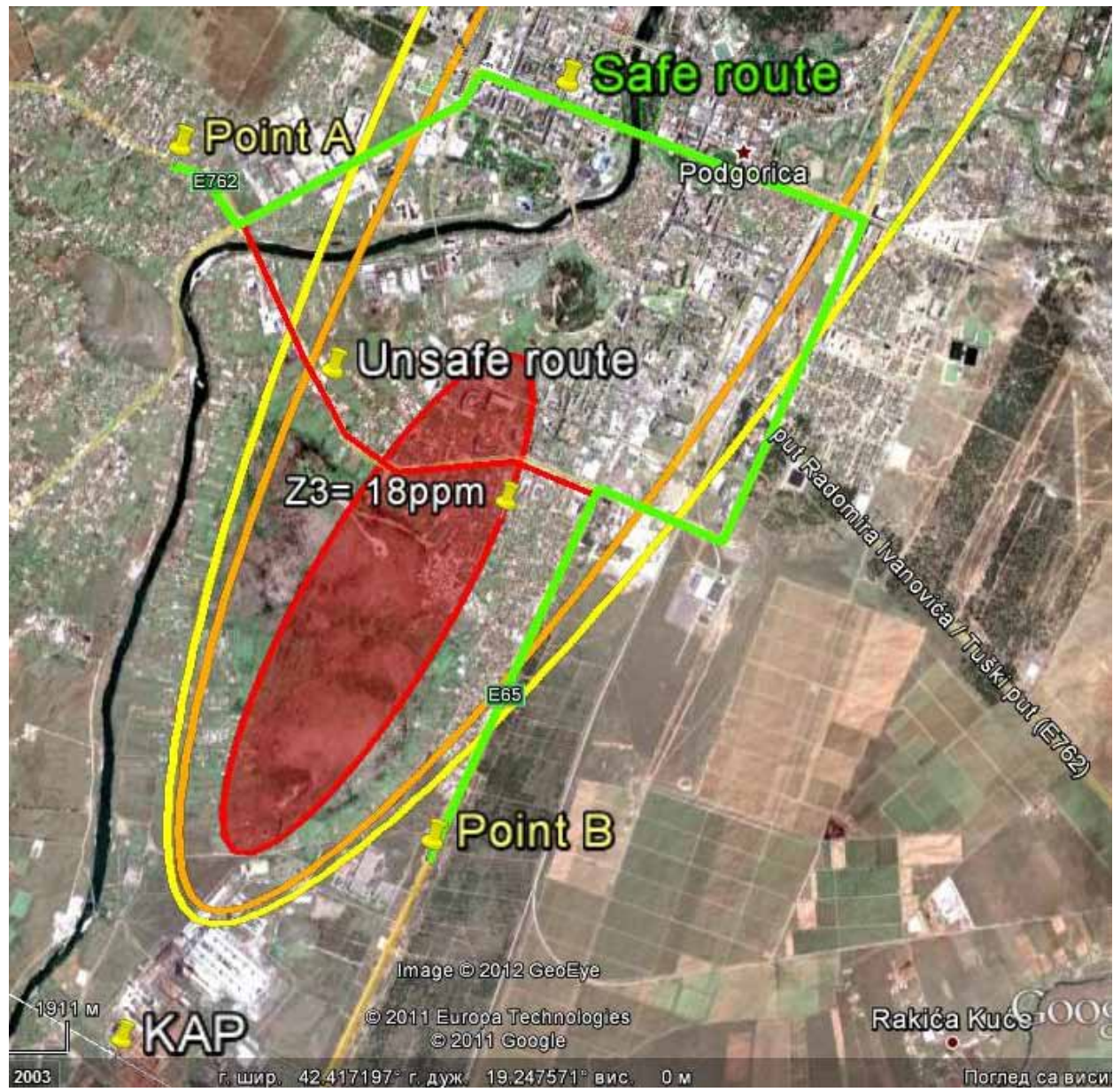

Figure 7: Shortest traffic path in case of an accident at the KAP

weather conditions. In addition to evacuation from the RED zone, the traffic through this zone must be redirected towards the shortest safe route. The driver travels from Point A (road E762) to Point B (road E65). Normally, the shortest way is going through the RED zone (red color path - Unsafe route). The GEPSUS system calculates the Safe route (green path), according to the algorithm given in Section 4, and police patrols redirect traffic on this route.

\section{Conclusions}

The paper elaborates upon recent developments in the GEPSUS project related to the simulation of hazardous gases releases in urban areas. The structure of the response system from aspects of data importing, modeling and simulation, decisionmaking, graphical visualization over Google Earth, as well as the results of testing and validation are presented. In case of an accidental or deliberate atmospheric release, the GEPSUS system is able to determine the threat zones, unsafe area and safe traffic routes for purposes of emergency responders. The system is GIS based, web-oriented and its services and outputs can be accessed by standard ICT equipment. Hazardous gas releases is an unpredictable process and thus decision-making has its own uncertainties. However, the GEPSUS tool can sup- port improved decision-making. In future the system will be enhanced with additional features in terms of hazard sources, automated data entry, and a wide range of decision options.

\section{References}

Abbaspoura, M. \& Mansourib, N. (2005). City hazardous gas monitoring network. Journal of Loss Prevention in the Process Industries, 18(4-6), 481-487, http://dx.doi.org/10.1016/j. jlp.2005.07.023

Baumann-Stanzer, K. \& Stenzel, S. (2011). Uncertainties in modeling hazardous gas releases for emergency response. Meteorologische Zeitschrift, 20(1), 19-27, http://dx.doi.org/10.1127\%2F09412948\%2F2011\%2F0506

Beychok, M.R. (2005). Fundamentals of Stack Gas Dispersion (4th Edition ed.). ISBN 0-9644588-0-2.

Briggs, G.A. (1965). A plume rise model compared with observations. Journal of the Air Pollution Control Association, 15, 433438, http://dx.doi.org/10.1080\%2F00022470.1965.10468404

Chitumalla, K.P. \& Harris, D., Thuraisingham, B., \& Khan, L. (2008). Emergency response applications dynamic plume modeling and real-time routing. IEEE Internet Computing, 12 (1), 38-44, http://dx.doi.org/10.1109\%2FMIC.2008.11

Cormen, T. H., Leiserson, C., E., Rivest, R., L. \& Stein, C. (2001). Introduction to Algorithms. Second Edition. MIT Press. 
De Amicis, R., Stojanovic, R. \& Conti, G. (2009). GeoSpatial Visual Analytics: Geographical Information Processing and Visual Analytics for Environmental Security. Springer. NATO Science for Peace and Security Series C: Environmental Security

Kurashiki T., Zako M. \& Fumita M. (2005). A practical estimation method of safety and reliability for chemical plants. Proc. 9th International Conference on Structural Safety and Reliability, Rome, Italy, June 20-23, pp. 703-708.

OpenGL (2012). Retrieved January 12, 2012, from http://www. opengeospatial.org/standards $/ \mathrm{kml}$

Pontiggia, M., Derudi, M., Alba, M., Scaioni, M. \& Rota, R. (2010). Hazardous gas releases in urban areas: Assessment of consequences through CFD modeling. Journal of Hazardous Materials, 176(1-3), 589-596, http://dx.doi.org/10.1016\%2Fj. jhazmat.2009.11.070

Škraba, A., Kljajić, M. \& Leskovar, R. (2003). Group exploration of SD models - Is there a place for a feedback loop in the decision process? System Dynamics Review, 19(3), 243-263, http:// dx.doi.org/10.1002/sdr.274

Tiwary, A. \& Colls, J. (2009). Air Pollution, Measurement, Modelling and Mitigation. Third Edition. Taylor \& Francis.

Radovan Stojanović obtained Dipl. Ing. degree from University of Montenegro and Ph.D. from University of Patras, Greece in field Electrical Engineering and Computer Engineering. Currently he is an associate professor at University of Montenegro where leads the Applied Electronics Centre. He was/is a leader of numerous EU, NATO, Bilateral and National programs and an author of more than 120 publications in international monographs, journals, conference and workshop proceedings as well as a member of prestige scientific committees and associations. Additionally, he has considerable industrial experience.

Andrej Škraba obtained his Ph.D. in the field of Organizational Sciences from the University of Maribor. $\mathrm{He}$ works as a researcher and assistant professor at the Faculty of Organizational Sciences, University of Maribor in the Cybernetics and DSS Laboratory. His research interests cover modeling and simulation, systems theory and decision processes. He is a member of System Dynamics Society and SLOSIM.

Marko Dragović graduated from University of Montenegro, Faculty of Electrical Engineering. He is NATO scholarship holder in GEPSUS project.

Nedjeljko Lekić received his B.S.E.E., M.S.E.E. and PhD degrees from University of Montenegro, in 1993, 1999 and 2006 respectively. From 1993 to the end of 1995 he was with company, Electromechanic Engineering, at Podgorica. From December 1995 he was with Electrical Engineering Department at University of Montenegro. Currently he is a docent at University of Montenegro, Department of Electrical Engineering. His basic research interests are in applied electronics (analog and digital), identification system, database, industrial electronics, hardware-software co design, microprocessor-based design and embedded systems.
Simon M. Berkowicz completed his M.Sc. in Applied Geography (climate) at the University of New South Wales. $\mathrm{He}$ is presently a researcher and coordinator in the Arid Ecosystems Research Center and the Interuniversity Institute for Marine Sciences, both at the Hebrew University of Jerusalem. His research areas have encompassed topoclimate, microclimate, arid ecosystems, and environmental studies. He has published about 30 scientific articles and served as a co-editor of 8 books.

Raffaele De Amicis is the Managing Director of Fondazione Graphitech. He holds a MEng in Mechanical Engineering and a Ph.D. on 'Surface Modelling in Virtual Environments'. His research fields span from CAD, virtual reality, virtual engineering, geovisual analytics, science and technology policy. He has authored 3 books, contributed to 11 scientific texts, and he is author or co-author of more than 120 scientific papers. He is coordinator of two EU projects and Nato Country Project Director of GEPSUS.

Giuseppe Conti is a Senior Researcher at Fondazione Graphitech. He received a MEng in Civil Engineering and a $\mathrm{PhD}$ degree in collaborative virtual environments at urban scale. He has also worked for international engineering consultants in the UK and has been involved in several EU and industrial projects dealing with issues related to the use of Virtual Reality in planning, large terrain 3D visualization and in the use of geobrowsers. He has $100+$ publications in the field of computer graphics and applications.

Davorin Kofjač received his Ph.D. from the University of Maribor in the field of Management of Information Systems. $\mathrm{He}$ has published several papers in international conferences and journals, and has been involved in many national research projects. Currently, he is working as a researcher at the same university. His research interests include modeling and simulation, artificial intelligence and operational research.

Doron Elhanani is an expert for prevention, protection and response to emergency and security threats, such as conventional and non-conventional terror attacks, Low Intensity Threats (LIC), nature disasters and other crisis situations. He is President \& CEO of EMESCO and member of Presidency of the Manufacturers Association of Israel.

Gojko R. Nikolić gained his Ph.D. from the University of Montenegro, Institute for Geography, Niksic, in the field of mapping and geographic information and physical-geographical disciplines. He participated as an associate or a member of professional teams in the development of more scientific studies and research projects-including international, in which his professional and scientific engagement was focused to solve methodological problems, making the redaction of numerous maps, atlases, and topographic and geographic and GIS base from several fields of science (GIS and Digital cartography, Environmental, Physical planning and Geoecology). 